\title{
LAS SOCIEDADES PRIVADAS DE LOS ENTES LOCALES
}

\author{
por \\ Francisco Lliset Borrell \\ Profesor titular de Derecho Administrativo
}

SUMARIO: I. INTRODUCCION--I. EL REGIMEN JURIDICO DE LA ORGANIZACION.-III. EL PERSONAL.-IV. LOS BIENES.-V. LA CONTRATACION DE LAS SOCIEDADES PRIVADAS MUNICIPALES.-VI. LA RESPONSABILIDAD PATRIMONIAL DE LAS SOCIEDADES PRIVADAS. SU REGIMEN JURIDICO. LA TECNICA DE PENETRACION DE LA PERSONALIDAD.

\section{INTRODUCCION}

A diferencia de los organismos autónomos que están encuadrados orgánicamente en la Administración, las Sociedades privadas no responden a un encuadramiento orgánico sino a una vinculación patrimonial.

Tanto la organización como la actividad de estas Sociedades es de Derecho privado. A través de sus Sociedades la Administración no actúa, por tanto, ope imperii, sino ope propietatis. Sin embargo, hay aspectos respecto de los que el Derecho administrativo no es ajeno (nombramiento de cargos, financiación, orientación general de sus fines, ciertas técnicas de control, acuerdos de creación de la empresa, adquisición y enajenación de títulos, autorizaciones para operaciones crediticias, régimen de beneficios, etc.), bien por estar regulados en normas administrativas, bien por estar incluidos en el acuerdo de creación, forme parte o no del contenido de los Estatutos. 
Junto a los aspectos jurídico-administrativos puros y a los aspectos jurídico-privados puros cabe situar las normas de Derecho privado singular de estas Sociedades, tales como las normas sobre contratación contenidas en la D.T. 2 del Reglamento de Contratación del Estado. Si estas normas fueran de Derecho público, los contratos celebrados sin tener en cuenta las reglas, de preparación y adjudicación, serian nulos por tratarse de un vicio de orden público declarable de oficio por los Tribunales. Si estas normas son privadas no cabrá la anulabilidad del contrato, sino la mera responsabilidad de los gestores (1).

Otras normas de este Derecho singular son, por ejemplo, la derogación de la proporcionalidad de derechos y participaciones en el capital, la derogación del principio de pluralidad de socios, etc. (2).

Que existan aspectos de Derecho público a los que han de someterse las Sociedades de ente público no repugna a su naturaleza jurídico-privada. En el supuesto de Sociedades de servicio público sería absurdo que éstas estuvieran menos disciplinadas que las Sociedades concesionarias. La ley del servicio establece un estatuto público del que derivan derechos y obligaciones para la Administración, el gestor y los usuarios. Es indudable que la Administración tiene la disponibilidad de la ley del servicio, y que la incidencia de las modificaciones de éste sobre la situación del gestor es de carácter externo, permaneciendo privado el régimen jurídico básico de la Sociedad. No otro es el mecanismo que disciplina a las Sociedades concesionarias (3).

Las Sociedades de mercado, propiedad de los entes públicos, tienen fines de utilidad pública, y es, cabalmente, esa utilidad pública, la que podría demandar una reglamentación, análoga a los servicios privados de interés público, virtuales o impropios (taxis, bancos, farmacias, etc.) y, por tanto externa, y que no afecta al régimen privado de la Sociedad. No obstante, tales normas de policía administrativa podrían atentar, en cuanto afectaren a empresas de mercado, al principio de libertad de comercio. Si el régimen privado resulta inadecuado, debiera modificarse la forma de gestión y no derogar alguno de sus aspectos, más allá de lo previsto por el ordenamiento general (4).

(1) Clavero Arevalo, M. F.: Municipalización y Provincialización de servicios en la LRL, Madrid, 1952, y ARIÑo, G.: La empresa pública en el modelo económico en la Constitución española, vol. 2, Madrid, págs. 13 y sigs.

(2) Alonso Ureba, A.: La empresa pública, Montecorvo, 1985, y Duque, J. F.: "La Sociedad privada municipal, REVL, 179, 1973.

(3) Escribano, P.: «El usuario ante los servicios públicos», RAP, 82, pág. 113.

(4) Alonso UreBa, A.: op. cit. 


\section{EL REGIMEN JURIDICO DE LA ORGANIZACION}

Pese a la identidad de los miembros de la Corporación Local y de la Junta General de las Sociedades locales se trata de dos órganos, no sólo distintos sino de persona jurídica distinta, una de Derecho público y otra de Derecho privado.

Esto constituye una importante novedad en el campo de las Sociedades de ente público. Las Juntas Generales en las Sociedades íntegramente estatales o integramente autonómicas no tienen ningún papel que cumplir. La exigencia formal de este órgano por la LSA no justifica en absoluto su pervivencia. Pero en la esfera local, la posibilidad de que los niveles de la Corporación se reencuentren, con su diversidad de pareceres, en el órgano supremo de la Sociedad, hace de la Junta General un órgano extremadamente útil y, por demás, un órgano en que el Municipio reencuentra, bajo formas de derecho privado, sus esencias democráticas.

Justamente por esto, y a diferencia de los demás órganos de la Sociedad -el Consejo de Administración y el Gerente-, la Junta General no acaba de desprenderse del todo del ordenamiento administrativo que pasa a formar parte del Derecho especial de la empresa pública local (art. 92 RSCL).

Es obvio que en el contenido de los acuerdos se estará a las leyes mercantiles y a los Estatutos, dentro de la especialidad del objeto social. Pero en las cuestiones formales - principio de colegialidad y su impugnación- la remisión al Derecho administrativo es clara (5).

Los asuntos que hayan de someterse a Junta General se tramitarán por el órgano administrativo de gestión que corresponda o, si procede, por la propia Gerencia de la Sociedad, y los expedientes se entregarán en la Secretaría de la Corporación que, después de examinarlos, los someterá al Presidente para formar el orden del día de la Junta (artículo 177 ROF).

La adopción de acuerdos por la Junta se someterá al principio de colegialidad, en los términos de la legislación local, en cuanto a convocatoria, quórum de constitución, régimen de debates, quórum de votación, publicación y comunicación de acuerdos, etc. (6).

El régimen de impugnación de acuerdos, que forma parte del procedimiento administrativo, no se regirá por la Ley de Sociedades Anó-

(5) Duque, J. F.: op. cit.; AlBI, F.: Tratado de los modos de gestión de las Corporaciones Locales, M., 1960, y Pérez MORENo, A.: La forma juridica de las empresas públicas, Sevilla, 1969.

(6) Luset Borrell, F.: Manual de Derecho local, 2.a ed., Madrid, 1986. 
nimas, concebido para la defensa de los socios minoritarios, sino por el régimen jurídico-administrativo concebido para la defensa del interés público y el respeto a los derechos privados. Por ello, los acuerdos de las Juntas Generales, que no gozan del privilegio de la ejecutividad, por ser éste incompatible con el régimen de la Sociedad privada, podrán ser impugnados en los términos del artículo 65 LBRL por la Administración del Estado y de la respectiva Comunidad Autónoma, los propios miembros de la Corporación y los titulares de derechos e intereses legítimos. Pero el ámbito de conocimiento de los Tribunales Contencioso-administrativos se reducirá a los aspectos de funcionamiento o principio de colegialidad. No existen aqui actos administrativos separables de los actos mercantiles, pero sí aspectos administrativos separables (funcionamiento del órgano) de los aspectos mercantiles de fondo, ambos referidos a un mismo acto (7).

El Consejo de Administración de las Sociedades de Estado o de Comunidad Autónoma es, a veces, designado por la Administración, pero esto no puede ocurrir legalmente en las Sociedades de ente local en las que, existiendo Junta General, que falta normalmente en aquéllas, es este órgano societario el que designa los miembros del Consejo de Administración, con arreglo a la legislación mercantil.

En la composición se prima a los técnicos o expertos sobre los representantes políticos, sin que éstos puedan exceder de la tercera parte. Esta limitación no es de Derecho administrativo sino de Derecho privado singular sólo enjuiciable por la Jurisdicción ordinaria (8).

\section{III. . EL PERSONAL}

El personal al servicio de las Sociedades de ente público ha de ser exclusivamente personal laboral, ya que dichas Sociedades son de la Administración pública, pero no son Administración pública (9).

(7) En el texto se media en la polémica entre las dos tesis de purismo monolítico -Derecho administrativo o Derecho mercantil-, y se defiende la doctrina de los aspectos separables, paralela, aunque no coincidente, con la de los actos separables, construida en el seno de la teoría de los contratos de la Administración.

(8) El artículo 93.3 del Reglamento de Servicios de las Corporaciones Locales dice asi: "Los miembros de la Corporación podrán formar parte del Consejo de Administración hasta un máximo del tercio del mismo y afectarán a los Consejeros las incapacidades e incompatibilidades que para ejercer cargos representativos señalan la Ley y el ROF”.

(9) Garrido Falla, F.: Tratado de Derecho Administrativo, vol. II; existe edición de 1987. 
Debe mantenerse, consecuentemente, el principio de incomunicabilidad del personal de las Sociedades y la Administración matriz. Los funcionarios que pasen a una Sociedad quedarán en situación. de excedencia voluntaria por un máximo de 10 años y los servicios en ella no serán computados a efectos de trienios, como dejó bien sentado la STS de 17 de abril de 1968.

Los entes locales pueden tener personal funcionario o laboral, pero las Sociedades del ente local sólo laboral. El régimen de las relaciones contractuales de este personal será, en su integridad, el establecido en las normas de Derecho laboral (art. 11 TRRL). La cuestión es si son de aplicación a la Sociedades los principios de convocatoria pública (concurso, oposición o concurso-oposición libres) y los de igualdad, mérito y capacidad, así como el de publicidad, a los que se refiere el artículo 19 de la Ley 30/1984, de 2 de agosto, sobre Medidas para la Reforma de la Función Pública, y los artículos 91.2 y 103 LBRL.

Estos preceptos sólo pueden ser aplicados directamente a los entes locales y a los organismos autónomos, que son Administración pública, no a las Sociedades. Pero el hecho de que estas Sociedades, por ser instrumentales de la Administración, persigan inequívocamente el interés público, el ente socio y sus representantes deben acomodarse, como ocurre también en materia de contratación, a los principios constitucionales de igualdad (que comporta exigencia de publicidad), mérito y capacidad, aun cuando la doctrina mantenga dudas al respecto (10).

La incorporación al sector público demanda el respeto al principio de igualdad (art. 23.2 CE), así como al principio de eficacia (que comporta la exigencia del mérito y la capacidad); pero, repito, estas normas se dirigen no tanto a la Sociedad como al ente socio, el que a través de la Junta General debe hacerlos valer frente al Consejo de Administración (11).

Un ente socio que permita a su Sociedad que contrate personal sin atenerse a convocatorias pública que establezcan, además, criterios y procedimientos objetivos de selección, no respetan el ordenamiento. La infracción de éste es cometida, empero, por el ente socio y no por la Sociedad.

(10) ARIÑo, G.: op. cit., pág. 196.

(11) Garcí Torres, J., y Jimenez Blanco, A.: Derechos fundamentales y relaciones entre particulares, Civitas, 1986. 


\section{LOS BIENES}

No es infrecuente que en la constitución de Sociedades privadas de ente público, el socio único, que es la Administración titular de un servicio público, efectúe el desembolso del capital social, en todo o en parte, mediante bienes demaniales, y más en concreto, mediante los bienes que constituyen el soporte del servicio público (cementerio, instalaciones del suministro de aguas, etc.).

Doctrinalmente se han mantenido tesis favorables a la aprobación y el mantenimiento en el patrimonio de la Sociedad de bienes de dominio público (12). Esta posición se basa en una concepción objetiva del dominio público, caracterizada por la afectación o vinculación a un fin público sin que precise de la titularidad. La titularidad puede ser privada, pero no por ello la Administración pierde sus potestades administrativas sobre el bien. De esta forma los bienes pueden estar en el tráfico jurídico, en el comercio privado, sin merma para su vinculación al destino público que es, en definitiva, lo que de verdad importa (13).

La tesis expuesta es sugestiva, porque incluso resolvería la cuestión de la propiedad de los concesionarios, sin perjuicio del ejercicio por la Administración de las potestades administrativas sobre los bienes y sobre la actividad, y sin perjuicio de la reversión, al final del plazo, de los bienes o de la empresa (de servicio público), o ambos a la vez.

Esta posición, que puede mantenerse, de lege ferenda, y que incluso sería útil, no puede adoptarse con base en el Derecho positivo actual, que parte de una concepción definitoria del dominio público de la que deriva la exigencia de titularidad de una Administración pública. No puede haber, por tanto, titularidad de una Sociedad privada sobre los bienes demaniales. Ni éstos pueden ser aportados en el momento de constitución de la Sociedad, ni se convierten en demaniales por el hecho de afectarlos al servicio público. Pero, además de esa tesis dogmática, el mayor inconveniente viene de la necesidad de que los bienes aportados a la Sociedad respondan frente a los acreedores y sean, por ende, fácilmente transformables en dinero y susceptibles de embargo y ejecución. Si el patrimonio ha de cumplir una función de garantía ha de ser disponible, y no indisponibles como los que integran el dominio público.

(12) ROMERo HERNÁNDEZ, F.: «La empresa privada municipal y los bienes de servicio público", REDA, 47.

(13) Parejo, L.: RAP, 100-101. 
Las actuaciones de la Sociedad no descorren el velo de la persona juridica si no hay en ellas abuso o fraude, pero es obvio que responden con todos los bienes de su patrimonio (art. $89 \mathrm{RSCL}$ ), y no podrían hacerlo si dichos bienes fueran de dominio público, ya que el artículo 132 de la CE y los preceptos correspondientes de la LBRL prohíben que los bienes demaniales puedan constituir garantía alguna para los acreedores al ser inembargables y, por ende, sustraídos a la acción de los acreedores. Esta es, por otra parte, la doctrina de la DGRN, de 12 de septiembre de 1985 (14).

La Sociedad puede ser titular, no obstante, de derechos reales, no dominicales, sobre el dominio público, igual a como puede serlo un concesionario. Estos derechos serán evaluados con arreglo a las normas técnicas o legales de valoración, contabilizados por la Sociedad e inscritos a su nombre en el Registro de la Propiedad (15).

Con respecto a los bienes patrimoniales sí que cabe que sean aportados a la Sociedad, porque las aportaciones sociales pueden ser dinerarias, pero también no dinerarias o en especie. La dificultad estriba en que la aportación a una Sociedad supone enajenación y ésta exige el procedimiento de subasta pública (RBCL) que, por otra parte, sería incompatible con la aportación, pues permitiría que los bienes quedasen desviados de la Sociedad en constitución. Los requisitos del expediente de enajenación y la subasta pública se exigen, ciertamente, para que los bienes puedan salir legalmente de la esfera patrimonial del sector público. En otro caso, incluso los bienes pueden ser cedidos gratuitamente a entidades $o$ a instituciones públicas para fines que redunden en beneficio de sus habitantes. Por ello, no es extraño que la LBRL y las disposiciones que desarrollan las formas de gestión de los servicios se remitan a la legislación mercantil para que, con arreglo a ella, los entes locales puedan constituir Sociedades con las adaptaciones que requieran las normas sobre servicios locales, quedando obviados para este supuesto las normas del Reglamento de Bienes.

Pero los bienes aportados ¿podrán ser enajenados, gravados, embargados sin restricciones? No pueden caber restricciones a los embargos, porque no se puede defraudar a los acreedores exigiendo autorizaciones de la Administración de cobertura, pero no parece procedente que a través de la constitución de la Sociedad los entes locales puedan obviar el obstáculo de la pública subasta (16). Por esto creo

(14) MENENDEZ, P.: «Sociedad privada municipal y aportación de bienes de dominio públicon, REDA, 47.

(15) GonzÁlez PERez, J.: Los derechos reales administrativos, Civitas, 1975.

(16) Duque, J. F.: "La Sociedad Privada Municipal», REVL, 179. 
que la enajenación voluntaria de bienes procedentes del ente local debe ser autorizada por la Administración de cobertura que, a su vez; deberá cumplir previamente todos los trámites legales. No así la enajenación de los bienes adquiridos por la Sociedad, sobre todo cuando son objeto de su tráfico mercantil, como ocurre con las Sociedades urbanizadoras de ente público.

El patrimonio y los caudales de la Administración local son inembargables (art. 4 LBRL). Este privilegio puede aplicarse, asimismo, a los bienes y caudales de los organismos autónomos, pero no a los bienes y caudales de las Sociedades privadas de ente público. Estas Sociedades han de ser demandadas ante los Tribunales ordinarios y las Sentencias de éstos deberán ser ejecutadas por ellos mismos y no por la Administración. Los Tribunales ordinarios podrán, por ende, despachar mandamientos de ejecución contra los bienes y caudales de las Sociedades de ente público local, y proceder en su caso a la venta forzosa de aquéllos.

\section{LA CONTRATACION}

Uno de los motivos de huida del Derecho administrativo - por la Administración pública - es, justamente, el poder efectuar contrataciones civiles y mercantiles a través de la creación de Sociedades privadas.

No obstante, la Jurisprudencia (17) ha llegado a calificar como contrato administrativo el celebrado por una Sociedad Anónima municipal y una empresa constructora para la ejecución de obras de urbanización. La Sentencia utiliza la técnica de penetración de la persona jurídica e imputa el contrato a la Administración de cobertura, por tratarse de un servicio público.

Pero ocurre que la dogmática y la Jurisprudencia no admiten que se descorra el velo de la personalidad si no existe fraude de ley o abuso de derecho. Cuando no exista abuso o fraude, aunque se trate de obras y servicios de la Administración, si éstas son realizadas por una Sociedad privada, el contrato es privado y no administrativo. En otro caso se vaciarían de contenido las formas jurídico-privadas. Es, por tanto, la naturaleza del contrato -Administración o Sociedad- la que colorea de administrativo o de privado al contrato.

Las Sociedades de ente público (D.T. 2, RCE) "se sujetarán en materia de contratación de obras y suministros a sus normas especia-

(17) FERNÁNDEZ, T. R.: “¿Contratos administrativos entre personas privadas?», REDA, 1. 
les y a las que puedan dictarse sobre régimen jurídico de la empresa pública, aplicándose en su defecto los principios de la presente legislación, salvo que la naturaleza de la operación a realizar sea incompatible con aquéllos.

En particular se procurará respetar en su actuación, al objeto de conseguir un comportamiento homogéneo en todo el sector público, los siguientes principios:

- Rigurosa preparación de los proyectos, especificaciones y pliego de condiciones que sirvan de soporte al contrato.

- Atenerse a los principios de publicidad y concurrencia y estimular a éste el cumplimiento.

- Salvaguardar el interés de la entidad en el caso de incumplimiento del contratista."

Parece que las Corporaciones locales podrán incluir en los acuerdos de creación o en los Estatutos de la Sociedad Anónima disposiciones especiales sobre contratación, que tendrán la naturaleza de normas de régimen interior procedentes de la Administración; no en sus facultades de imperio, sino como propietaria. El mismo valor tendrán las normas emanadas de la Corporación constituida en Junta General. No se trata, pues, de derecho administrativo, sino de derecho mercantil, y a lo sumo de un ius privatum singulare.

En el sentido indicado por la D.T. 2 RCE, las disposiciones sobre contratación de obras y suministros, de un lado, y de adquisición de bienes, de otro, contenidas en el Estatuto de la empresa pública de Cataluña (18) serán aplicables, supletoriamente, como Derecho privado singular a las Sociedades de los entes locales de esta Comunidad Autónoma. Sólo las disposiciones que se refieren a la intervención previa de la Administración de cobertura tendrán carácter administrativo, pero las que afectan a la preparación de proyectos, publicidad y concurrencia deben considerarse como requisitos formales de la contratación privada de las Sociedades, cuyo enjuiciamiento corresponderá, en todo caso, a los Tribunales ordinarios, a diferencia de los actos separables de los contratos privados que celebre la Administración Pública, cuyo conocimiento, como es sabido, corresponde a la Jurisdicción Contencioso-administrativa.

Cosa distinta de los contratos de obras y suministros que regula, con carácter supletorio, la legislación de contratos del Estado y de los

(18) Nos referimos en el texto a la Ley 4/85, de 29 de marzo, del Estatuto de la empresa pública catalana, que se ha anticipado, aunque sigue fiel, con algunas innovaciones, a la regulación de la LEEA y a la LGT. Vid. LLSET BorreLL, F.: Codi de la legislació administrativa de Catalunya, Barcelona, 1987. 
de adquisición o enajenación de bienes (art. 5 LBRL) que se han de sujetar supletoriamente a la legislación del Patrimonio del Estado, es la contratación entre los usuarios y las Sociedades de ente público para utilización de los servicios (aguas, servicios funerarios, etc.). Estos contratos constituyen el tráfico mercantil ordinario de estas Sociedades, por lo que no existe en este punto modulación o singularidad alguna del Derecho privado, que es aplicable en toda su pureza. Quedan a salvo, por supuesto, los aspectos administrativos inherentes al servicio público (19).

\section{LA RESPONSABILIDAD PATRIMONIAL DE LAS SOCIEDADES PRIVADAS. SU REGIMEN JURIDICO. LA TECNICA DE PENETRACION DE LA PERSONALIDAD}

Las actuaciones que sean consecuencia del funcionamiento de los servicios públicos dan lugar a responsabilidad. Esta responsabilidad, en el caso de que los servicios sean gestionados por una Sociedad, cha de ser administrativa o civil? El artículo 123 LEF da pie a pensar que la relación jurídica que nazca sea consecuencia de daños causados por una Sociedad de ente público por el funcionamiento de servicios públicos, es administrativa y no civil. Este precepto indica que "cuando se trate de servicios concedidos la reclamación se dirigirá a la Administración que otorgó la concesión, dentro del año. La Administración habrá de decidir tanto sobre la procedencia de la indemnización como sobre quién debe pagarla. Esta resolución podrá ser impugnada en vía contencioso-administrativa" (20).

La indemnización deberá correr a cargo del concesionario, salvo el caso en que el daño tenga su origen en alguna cláusula impuesta por la Administración al gestor "y que sea de ineludible cumplimiento para éste" (art. 121.2 LEF).

Parece que si la responsabilidad es administrativa, cuando el gestor es absolutamente privado, con mayor motivo deberá serlo si es una Sociedad de ente público de carácter instrumental.

Este tipo de responsabilidad no se basa en la técnica de la penetración o transparencia de la persona jurídica, sino en el control de la Administración titular del servicio, que causaliza la resolución por vía administrativa, pero no por ello asume la responsabilidad que por regla general será de la Sociedad. El velo de la personalidad de ésta no

(19) SALAS, J.: «Sobre la naturaleza de las relaciones entre los usuarios», REDA, 4.

(20) Vid. nota 11. 
se descorrerá mientras no mediara abuso o fraude de la Administración titular en el manejo de su ente instrumental (21).

Incluso cabe pensar que la Sociedad pueda impugnar la resolución de la Administración de cobertura. No se opone a ello a nuestro juicio el artículo 28.4. $a$ LJC, que excluye a los órganos de la Administración, ni el artículo 28.4. $b$ de la LJC, que excluye del recurso a "los particulares cuando obraren por delegación o como meros agentes o mandatarios de ellan - la Administración que dictó el acto-.

La Sociedad no es, en efecto, un órgano, ni es un delegado, agente o mandatario, sino una persona distinta con la encomienda de gestionar, bajo su responsabilidad, un servicio o actividad.

Otra cosa es que por la confusión de miembros de los órganos de la Corporación y de la empresa, la impugnación de la decisión administrativa de la Administración de cobertura no se produzca. La tensión y el conflicto interpersonales son posibles y su canalización jurídica sería, en este caso, la indicada.

(21) ARINo ORTIz, G.: La Administración institucional, IEA, pág. 126, y DE CASTRo, F.: Formación y deformación del concepto de persona juridica, Madrid, 1965, págs. 11 y sigs. 
